\author{
A. Biloshchytskyi \\ Doctor of Technical Sciences, Professor, Vice-Rector for \\ Science and Innovation \\ a.b@astanait.edu.kz, orcid.org/0000-0001-9548-1959 \\ Astana IT University, Kazakhstan \\ Professor of Information Technologies Department \\ Kyiv National University of Construction and \\ Architecture, Ukraine
}

\title{
USE OF VECTOR ALGEBRA TO ENSURE THE INTEGRITY OF THE COMPONENTS OF THE PROJECT-VECTOR MANAGEMENT MULTISYSTEM OF EDUCATIONAL ENVIRONMENTS
}

\begin{abstract}
The article is devoted to the development of a mathematical model of the projectvector space of educational environments. Mathematical formalization of the project-vector space is performed. The main directions of application of vector algebra to ensure the integrity of the components of multisystem of project-vector management of educational environments are proposed. It is shown that in order to build an effective project management system, it is not so much the direction of movement of individual objects that is important, but the same or different vectors of their movement in the project-vector space. The same vectors mean that the movement of objects of different projects is equally conditioned. A model for calculating the distances between vectors and determining the optimal set of project groups (respectively, subsystems of the project management system) is proposed. Mathematical models have been developed for estimating the magnitude of the similarity of vectors over significant time intervals, as well as estimating the magnitude of the proximity of vectors specified by qualitative categories. These models show that the slower the objects of various projects move relative to each other, the more profitable it is to attribute them to one group and manage them on the basis of a single component of a multi-project management system.

Keywords: project-vector space, educational environments, vector algebra, distance between vectors.
\end{abstract}

\section{Introduction}

The successful solution of the problems facing the Republic of Kazakhstan on the way of its integration into the world economy is impossible without specialists with a high level of qualification. The changes necessary for this in the education system of the Republic of Kazakhstan are in such organizational, technological, functional improvements that allow reaching the level of leading European educational institutions. It is necessary to improve not only educational institutions, but also all educational environments of the Republic of Kazakhstan, formed by legislative, executive and territorial government bodies, including education management and various educational, scientific, scientific, methodological and other institutions [1-3].

To ensure the effectiveness of the actions of training professionals, it is necessary to carry out a structural restructuring of the entire mechanism of managerial activity in educational 
environments. Such a restructuring is associated with the need to move to the use of project management methodology in organizing management activities in all institutions involved in the training of specialists or involved in such training [4, 5].

The transition to project management in educational environments requires the creation of such a project management methodology that takes into account the specifics of measures aimed at training specialists. This methodology should provide both economic activities, and activities for the organization of the educational process and the scientific work of educational institutions with new project management tools [6-9].

As a result of the decomposition of the subject area, in [10-12] the classification of projects of educational environments was carried out and the problem of optimal control in the projectvector space was formulated. The performed studies allow us to move on to the formalization of the processes of managing educational environments. Let's set the basic definition of this part of the work.

Definition 1. Under the project-vector management of educational environments, we mean the implementation of functions that ensure the organization, planning and control of the distribution of available resources between the objects of educational environments and ensure their fastest possible progress in the project-vector space.

Mathematically, the multisystem of project-vector management of educational environments will reflect the vectors formed in the project-vector space (the direction of change of objects), evaluate and adjust them based on the needs of stakeholders and project goals. The projectvector space contains a set of objects and subjects of projects developing in time. The development of objects and subjects of projects corresponds to the movement in the projectvector space. Therefore, the evaluation of the effectiveness of the multisystem of projectvector management of educational environments will be carried out through an assessment of the distance between vectors that reflect the required and actual development of objects and subjects of projects.

Mathematically, single movements of objects and subjects of projects in a discrete projectvector space can be represented by a set of vectors. Each coordinate of the vector displays the place of the object/subject of the project in one of the dimensions at the current time. The end point of these movements is the end of the project and again the collapse of the project-vector space (for the project that ended) into a point.

Each vector is given by coordinates that reflect the state at some discrete time $t$ of the object/subject $Q_{j}$ of the project $\Pi_{k}$ in the project space $\Omega$.

$$
A_{k}^{(j)}(t)=\left[\mathrm{x}_{\mathrm{k} 1}^{(\mathrm{j})}(\mathrm{t}), \mathrm{x}_{\mathrm{k} 2}^{(\mathrm{j})}(\mathrm{t}), \ldots, \mathrm{x}_{\mathrm{ki}}^{(\mathrm{j})}(\mathrm{t}), \ldots, \mathrm{x}_{\mathrm{kp}}^{(\mathrm{j})}(\mathrm{t})\right]
$$

where $\mathrm{x}_{\mathrm{ki}}^{(\mathrm{j})}(\mathrm{t})$ - the value of the coordinate of the object/subject $Q_{j}$ of the project $\Pi_{k}$ along the axis $N_{i}$ in the project-vector space at time $t$.

The motion vector determines priority measurements (priority values of the project) and is determined through the amount of distance change in given directions per time quantum.

To build an effective project management system, it is not so much the "aspirations" of individual objects that are important, but how similar or different the vectors of their movement in the project-vector space are. After all, the same vectors mean that the movements of objects of different projects are equally predetermined. Consequently, a single system (or subsystem) for managing these projects can be created.

To create an effective multi-project management system, it is necessary to group projects in such a way that the distance between the vectors of projects included in one group is minimal. 
The coordinates of the vectors in each of the dimensions are as different as the signs of the objects and subjects of the projects that are displayed in this dimension. It is necessary to develop a mathematical apparatus for calculating the distance between the directions of development of objects and subjects of projects. This will make it possible to create optimal functional procedures for the formation of vectors and minimize the time / cost for creating a multisystem of project-vector management of educational environments.

We use the mathematical apparatus of vector algebra to calculate the distances between vectors and determine the optimal set of project groups (and, accordingly, subsystems of a multiproject management system).

\section{Determining the proximity of vectors in the project-vector space.}

Let for a certain period of time $d t$ the value of the coordinates of some object/subject $Q_{j}$ of the project $\Pi_{k}$ change from the value:

$$
\left|\mathrm{x}_{\mathrm{k} 1}^{(\mathrm{j})}(\mathrm{t}-\mathrm{dt}), \mathrm{x}_{\mathrm{k} 2}^{(\mathrm{j})}(\mathrm{t}-\mathrm{dt}), \ldots, \mathrm{x}_{\mathrm{ki}}^{(\mathrm{j})}(\mathrm{t}-\mathrm{dt}), \ldots, \mathrm{x}_{\mathrm{kp}}^{(\mathrm{j})}(\mathrm{t}-\mathrm{dt})\right|,
$$

up to value

$$
\left|\mathrm{x}_{\mathrm{k} 1}^{(\mathrm{j})}(\mathrm{t}), \mathrm{x}_{\mathrm{k} 2}^{(\mathrm{j})}(\mathrm{t}), \ldots, \mathrm{x}_{\mathrm{ki}}^{(\mathrm{j})}(\mathrm{t}), \ldots, \mathrm{x}_{\mathrm{kp}}^{(\mathrm{j})}(\mathrm{t})\right|,
$$

where $t \quad-$ is the moment of time;

$d t$ - time quantum of the discrete project-vector space.

Then the value corresponding to the development of the object/subject $Q_{j}$ of the project $\Pi_{k}$, can be determined from the formula.

$$
l_{\mathrm{k}}^{(\mathrm{j})}(\mathrm{t})=\sqrt{\sum_{i=1}^{p}\left(\mathrm{x}_{\mathrm{ki}}^{(\mathrm{j})}(\mathrm{t})-\mathrm{x}_{\mathrm{ki}}^{(\mathrm{j})}(\mathrm{t}-\mathrm{dt})\right)^{2}},
$$

where $l_{\mathrm{k}}^{(\mathrm{j})}(\mathrm{t}) \quad-\quad$ vector estimate of the change in the object/subject $Q_{j}$ of the project $\Pi_{k}$

But there is one peculiarity in the project-vector space. In operations on vectors, the distance between them in some dimension is given by the difference in coordinates in that dimension. This cannot be used to calculate the degree of proximity of different vectors. Firstly, due to the fact that the direction of development of an object/subject cannot be assessed by small discrete points in time. It is necessary to evaluate them over a sufficiently long time interval.

Secondly, the creation of a single system (subsystem) for managing many projects is based not only on the "unidirectionality" of the development of individual objects and subjects of projects, but also on their proximity in the project-vector space. For example, whether the same methods or project management tools are used, the same performers, whether the same input information is used.

Solution of these two problems.

\section{Estimation of the magnitude of the similarity of vectors on significant time intervals}

Expression (1) determines the direction of development of the object/subject $Q_{j}$ of the project $\Pi_{k}$ in the project-vector space at the moment $t$ (figure 1). 


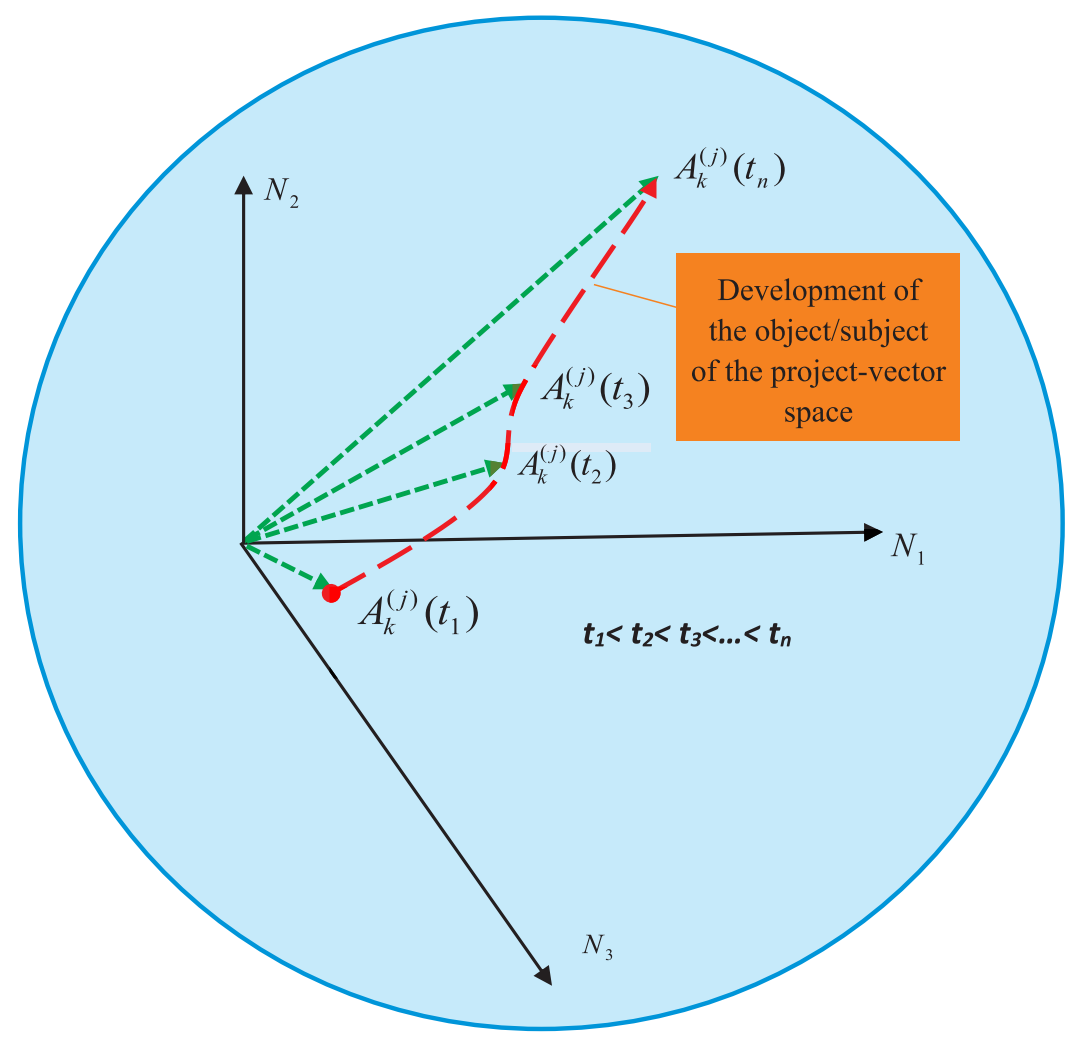

Fig. 1. Illustration of the development of objects and subjects of projects in a three-dimensional project-vector space

$$
\begin{aligned}
& A_{k}^{(j)}(t)=\frac{d A_{k}^{(j)}(t)}{d t}=\left[\frac{\mathrm{dx}}{\mathrm{kt}(\mathrm{t})}, \frac{\mathrm{dx} \mathrm{x}_{\mathrm{k}}^{(\mathrm{j})}(\mathrm{t})}{\mathrm{dt}}, \ldots, \frac{\mathrm{x}_{\mathrm{ki}}^{(\mathrm{j})}(\mathrm{t})}{\mathrm{dt}}, \ldots, \frac{\mathrm{dx}_{\mathrm{lp}}^{(\mathrm{j})}(\mathrm{t})}{\mathrm{dt}}\right] ; \\
& A_{r}^{(j)}(t)=\frac{d A_{r}^{(j)}(t)}{d t}=\left[\frac{\mathrm{dx} \mathrm{r}_{\mathrm{r} 1}^{(\mathrm{j})}(\mathrm{t})}{\mathrm{dt}}, \frac{\mathrm{dx}_{\mathrm{r} 2}^{(\mathrm{j})}(\mathrm{t})}{\mathrm{dt}}, \ldots, \frac{\mathrm{x}_{\mathrm{ri}}^{(\mathrm{j})}(\mathrm{t})}{\mathrm{dt}}, \ldots, \frac{\mathrm{dx}_{\mathrm{rp}}^{(\mathrm{j})}(\mathrm{t})}{\mathrm{dt}}\right],
\end{aligned}
$$

where $A_{k}^{(j)}(t) \quad$ - instantaneous object/subject motion vector $Q_{j}$ of the project $\Pi_{k}$ at the time $t$;

$A_{r}^{(j)}(t) \quad$ - instantaneous object/subject motion vector $Q_{j}$ of the project $\Pi_{r}$ at the time $t$.

If

$$
A_{k}^{(j)}(t) \approx A_{r}^{(j)}(t)
$$

Then this means that at some point in time the projects develop in the same way. But this does not mean that the development of projects is similar over a long period of time, which means that uniform approaches can be applied to managing them. Therefore, to solve the problem of identifying projects that are close in development, we will use another mathematical model.

Replacing the minimum time interval with a larger one, which more accurately characterizes the coincidence or mismatch of trends in the development of projects. But not all vectors obtained from such a replacement are equivalent. After all, changes over a long period more accurately characterize the trends in the development of objects and subjects of projects. To more accurately determine the similarity of the management methodologies for various projects, let's set a weighting factor for determining similarity in the development of objects and subjects of the project-vector space. 
We get

$$
\begin{aligned}
& R\left(\frac{A_{k}^{(j)}(t)}{\Delta t}, \frac{A_{r}^{(j)}(t)}{\Delta t}\right)=R_{k r}^{(j)}(t, \Delta t)=\mu(\Delta t) \cdot\left|\frac{\Delta A_{k}^{(j)}(t)}{\Delta t}-\frac{\Delta A_{r}^{(j)}(t)}{\Delta t}\right|= \\
& =\mu(\Delta t) \cdot \sum_{i=1}^{p}\left|\frac{\mathrm{x}_{\mathrm{ki}}^{(\mathrm{j})}(\mathrm{t})-\mathrm{x}_{\mathrm{ki}}^{(\mathrm{j})}(\mathrm{t}-\Delta \mathrm{t})}{\Delta \mathrm{t}}-\frac{\mathrm{x}_{\mathrm{ri}}^{(\mathrm{j})}(\mathrm{t})-\mathrm{x}_{\mathrm{ri}}^{(\mathrm{j})}(\mathrm{t}-\Delta \mathrm{t})}{\Delta \mathrm{t}}\right|,
\end{aligned}
$$

Where $R\left(\frac{A_{k}^{(j)}(t)}{\Delta t}, \frac{A_{r}^{(j)}(t)}{\Delta t}\right)=R_{k r}^{(j)}(t, \Delta t)$ - difference in the direction of movement of the object/subject $Q_{j}$ in the projects $\Pi_{k}$ and $\Pi_{r}$ at the time $t ; \mu(\Delta t)$ - coefficient that specifies the value of the relationship between the value of the proximity of the vectors obtained for a given time interval and the actual proximity of the motion vectors of the object/subject $Q_{j}$ in the projects $\Pi_{k}$ and $\Pi_{r}$ at the time.

Since the longer the objects and subjects of projects develop in the same way, the more likely it is that the same approach is needed to manage them. Let us take as the value of the coefficient $\mu(\Delta t)$ the value of the time interval in which projects develop in the same way (almost the same way). Therefore, taking into account the coefficient $\mu(\Delta t)=\Delta t$

$$
\begin{aligned}
& R_{k r}^{(j)}(t, \Delta t)=\Delta t \cdot \sum_{i=1}^{p}\left|\frac{\mathrm{x}_{\mathrm{ki}}^{(\mathrm{j})}(\mathrm{t})-\mathrm{x}_{\mathrm{ki}}^{(\mathrm{j})}(\mathrm{t}-\Delta \mathrm{t})}{\Delta \mathrm{t}}-\frac{\mathrm{x}_{\mathrm{ri}}^{(\mathrm{j})}(\mathrm{t})-\mathrm{x}_{\mathrm{ri}}^{(\mathrm{j})}(\mathrm{t}-\Delta \mathrm{t})}{\Delta \mathrm{t}}\right|= \\
& =\sum_{i=1}^{p}\left|\mathrm{x}_{\mathrm{ki}}^{(\mathrm{j})}(\mathrm{t})-\mathrm{x}_{\mathrm{ki}}^{(\mathrm{j})}(\mathrm{t}-\Delta \mathrm{t})-\mathrm{x}_{\mathrm{ri}}^{(\mathrm{j})}(\mathrm{t})+\mathrm{x}_{\mathrm{ri}}^{(\mathrm{j})}(\mathrm{t}-\Delta \mathrm{t})\right|= \\
& =\sum_{i=1}^{p}\left|\left(\mathrm{x}_{\mathrm{ki}}^{(\mathrm{j})}(\mathrm{t})-\mathrm{x}_{\mathrm{ri}}^{(\mathrm{j})}(\mathrm{t})\right)-\left(\mathrm{x}_{\mathrm{ki}}^{(\mathrm{j})}(\mathrm{t}-\Delta \mathrm{t})-\mathrm{x}_{\mathrm{ri}}^{(\mathrm{j})}(\mathrm{t}-\Delta \mathrm{t})\right)\right|= \\
& =\left|\sum_{i=1}^{p}\left(\mathrm{x}_{\mathrm{ki}}^{(\mathrm{j})}(\mathrm{t})-\mathrm{x}_{\mathrm{ri}}^{(\mathrm{j})}(\mathrm{t})\right)-\sum_{i=1}^{p}\left(\mathrm{x}_{\mathrm{ki}}^{(\mathrm{j})}(\mathrm{t}-\Delta \mathrm{t})-\mathrm{x}_{\mathrm{ri}}^{(\mathrm{j})}(\mathrm{t}-\Delta \mathrm{t})\right)\right| .
\end{aligned}
$$

or, denoting

$$
\begin{aligned}
& l_{k r i}^{(j)}(t)=\mathrm{x}_{\mathrm{ki}}^{(\mathrm{j})}(\mathrm{t})-\mathrm{x}_{\mathrm{ri}}^{(\mathrm{j})}(\mathrm{t}) ; \\
& l_{k r i}^{(j)}(t-\Delta t)=\mathrm{x}_{\mathrm{ki}}^{(\mathrm{j})}(\mathrm{t}-\Delta \mathrm{t})-\mathrm{x}_{\mathrm{ri}}^{(\mathrm{j})}(\mathrm{t}-\Delta \mathrm{t}),
\end{aligned}
$$

where $\quad l_{k r i}^{(j)}(t) \quad$ - distance between object/subject motion vectors $Q_{j}$ of the projects $\Pi_{k}$ and $\Pi_{r}$ according to the measurement $N_{i}$ at the time $t$;

$A_{r}^{(j)}(t) \quad$ - distance between object/subject motion vectors $Q_{j}$ of the projects $\Pi_{k}$ and $\Pi_{r}$ according to the measurement $N_{i}$ at the time $t-d t$,

we get

$$
R_{k r}^{(j)}(t, \Delta t)=\sum_{i=1}^{p}\left|1_{\mathrm{kri}}^{(\mathrm{j})}(\mathrm{t})-1_{\mathrm{kri}}^{(\mathrm{j})}(\mathrm{t}-\Delta \mathrm{t})\right| \text {. }
$$

Then the average deviation in the management of different projects relative to a certain object/subject can be obtained by evaluating all the development vectors of this object

$$
\overline{R_{k r}^{(j)}(T, \Delta t)}=\frac{\int_{t=0}^{T} R_{k r}^{(j)}(t, \Delta t) d t}{T}=\frac{\int_{t=0}^{T} \sum_{i=1}^{p}||_{\mathrm{kri}}^{(\mathrm{j})}(\mathrm{t})-1_{\mathrm{kri}}^{(\mathrm{j})}(\mathrm{t}-\Delta \mathrm{t}) \mid d t}{T},
$$

where $\overline{R_{k r}^{(j)}(T, \Delta t)}$ - the average distance between the motion vectors of the object/subject $Q_{j}$ of the projects $\Pi_{k}$ and $\Pi_{r}$ in all measurements from the beginning of their implementation to time $T$. 


\section{Estimation of the proximity of vectors by qualitative criteria}

The proximity of vectors can be calculated from their coordinates, but it is difficult to apply a continuous numerical measure to many dimensions. After all, many project parameters are set by qualitative rather than quantitative parameters. Therefore, it is proposed to apply the inverse approach to determining the proximity of vectors. Each vector coordinate is represented by distances to the coordinates of other vectors (in this dimension) - the distance between project objects. For the same values of objects (even qualitative ones), the distance is equal to 0 . For different qualitative values - 1. In this case, there is no need to translate qualitative concepts into quantitative measures. Then the "reduced" coordinate of the end of the vector $A_{k}^{(j)}$ along the $N_{i}$ dimension will be given not by a single number, but by a tuple that displays the "differences" along this coordinate with the vectors of the same object, but of other projects:

$$
\overline{\mathbf{X}}_{\mathrm{ki}}^{(\mathrm{j})}=<l_{k 1 i}^{(j)}, l_{k 2 i}^{(j)}, \ldots, l_{k r i}^{(j)}, \ldots, l_{k K i}^{(j)}>
$$

where $\quad \overline{\mathbf{X}}_{\mathrm{ki}}^{(\mathrm{j})} \quad$ - the reduced coordinate of the end of the vector $A_{k}^{(j)}$ according to the dimension $N_{i}$ of the object/subject $Q_{j}$ of the project $\Pi_{k}$;

$l_{\mathrm{kri}}^{(\mathrm{j})} \quad$ - the reduced difference in the coordinates of project vectors $\Pi_{k}$ and $\Pi_{r}$ according to the $N_{i}$ for the object/subject $Q_{j}$;

$K \quad$ - number of projects.

To determine the similarity of projects, consider pairs of projects. When determining the proximity of each two projects in the project-vector space, not the entire tuple is important, but only a couple of values that characterize these projects. From this premise, it is possible to estimate the relative speed of movement (development) of objects of two different projects

$$
l_{\mathrm{kr}}^{(\mathrm{j})}(\mathrm{t})=\sqrt{\sum_{i=1}^{p}\left(\mathrm{l}_{\mathrm{kri}}^{\mathrm{j})}(\mathrm{t})-\mathrm{l}_{\mathrm{kti}}^{(\mathrm{j})}(\mathrm{t}-\mathrm{dt})\right)^{2}}
$$

where $l_{\mathrm{kri}}^{(\mathrm{j})}(\mathrm{t}) \quad$ - vector estimate of the change in the object/subject $Q_{j}$ of the project $\Pi_{k}$ according to the measurement $N_{i}$ at the time $t$ (instantaneous velocity of the displacement along the measurement) relative to the change in the same object/subject in the project $\Pi_{r}$;

$l_{\mathrm{kr}}^{(\mathrm{j})}(\mathrm{t}) \quad$ - vector estimate of the change in the object/subject $Q_{j}$ of the project $\Pi_{k}$ at the time $t$ (instant displacement velocity in the project-vector space) relative to the change in the same object/subject in the project $\Pi_{r}$;

where in

$$
\begin{gathered}
l_{\mathrm{kr}}^{(\mathrm{j})}(\mathrm{t})=l_{\mathrm{rk}}^{(\mathrm{j})}(\mathrm{t}) \\
\forall k, i, j: l_{k k i}^{(j)}=0 .
\end{gathered}
$$

Consequently, the slower two projects shift relative to each other, the more profitable it is to attribute them to one group and manage them on the basis of a single project management system (subsystem).

To determine the degree of proximity of vectors in the project-vector space, it is necessary to obtain the value of the distance for each coordinate with the vectors of the same object, but of other projects.

Let's set possible values of distances:

1. $1_{\mathrm{kri}}^{(\mathrm{j})}=1_{\mathrm{rki}}^{(\mathrm{j})}=1$ - the maximum distance determines the non-intersecting qualitative values of the coordinates (Fig. 2). For example, one project uses MS Project, another uses Primavera, or the projects are managed by different project managers. 


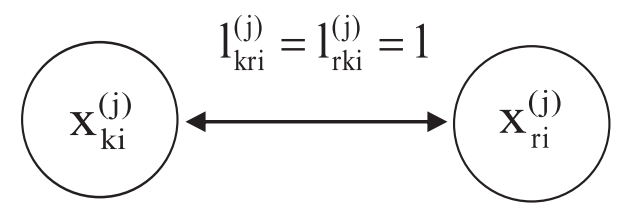

Fig. 2. The distance between non-intersecting qualitative values of the coordinates of the vectors of the project-vector space

2. $0<1_{\mathrm{kri}}^{(\mathrm{j})}=1_{\mathrm{rki}}^{(\mathrm{j})}<1$ - determines such filling of objects with qualitative concepts. It is equivalent to the fact that the components of the vectors in this dimension intersect (Fig. 3).

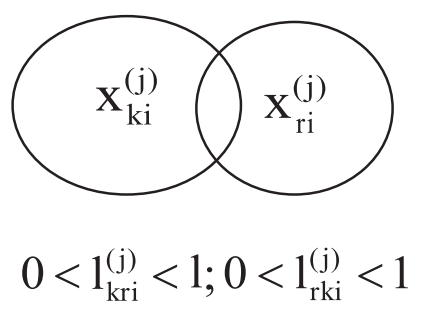

Fig. 3. The distance between the intersected qualitative values of the coordinates of the vectors of the project-vector space

3. $1_{\mathrm{kri}}^{(\mathrm{j})}=0 ; 0<1_{\mathrm{rki}}^{(\mathrm{j})}<1$ - defines the overlay of vectors. Corresponds to the entry of the components of one vector into another along the selected dimension (the projection of one vector onto the coordinate axis is included in the projection of another vector) (Fig. 4).

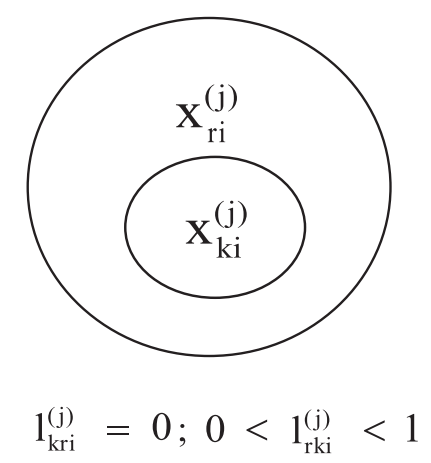

Fig. 4. The distance between vectors, provided that the qualitative value of the components of one vector is included in another vector of the project-vector space

4. $1_{\mathrm{kri}}^{(\mathrm{j})}=1_{\mathrm{rki}}^{(\mathrm{j})}=0$ - determines the coincidence of the qualitative components of different vectors. Means the correspondence of the components of one vector to another according to the selected dimension (the projection of one vector onto the coordinate axis coincides with the projection of another vector) (Fig. 5).

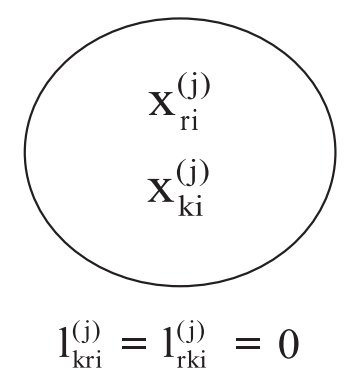

Fig. 5. The distance between vectors, provided that the qualitative value of the components of one vector coincides with the qualitative value of the components of another vector of the project-vector space 
To determine the numerical measure of the distance between vectors, let's set a numerical characteristic of the qualitative attributes of objects of different projects. Let for the object/ subject $Q_{j}$ of the project $\Pi_{k}$ in the context of the measurement $N_{i}$ it is given by a certain value $\mathrm{x}_{\mathrm{ki}}^{(\mathrm{j})}$. To determine the numerical value, we use the theory of fuzzy sets [4].

Then

$$
\mathrm{l}_{\mathrm{kri}}^{(\mathrm{j})}=\frac{\mathrm{s}\left(\overline{\mathrm{x}_{\mathrm{ki}}^{(\mathrm{j})}} \cap \overline{\mathrm{X}_{\mathrm{ri}}^{(\mathrm{j})}}\right)}{\mathrm{s}\left(\overline{\mathrm{x}_{\mathrm{ki}}^{(\mathrm{j})}}\right)}
$$

where

$$
\begin{gathered}
S\left(\overline{X_{\mathrm{ki}}^{(\mathrm{j})}}\right) \\
\mathrm{s}\left(\overline{\mathrm{X}_{\mathrm{ki}}^{(\mathrm{j})}} \cap \overline{\mathrm{X}_{\mathrm{ri}}^{(\mathrm{j})}}\right)
\end{gathered}
$$

- a fuzzy measure along the coordinate $N_{i}$ of the object/subject $Q_{j}$ of the project $\Pi_{k}$ in the project-vector space;

- a fuzzy measure of intersection of the atomic structure of the object/subject $Q_{j}$ in the projects $\Pi_{k}$ and $\Pi_{r}$ along the coordinate $N_{i}$ in the project-vector space.

The above model will make it possible to create a project management methodology focused on the educational environment, the components of which will reflect the specifics of the movement of close objects in the project-vector space.

\section{Conclusion}

It is shown that in order to build an effective project management system, it is important to reflect not so much the individual vectors of movement of objects and subjects of the projectvector space, as whether these vectors are the same or different. The creation of separate components of a multi-project management system is based not only on the "unidirectionality" of the development of individual objects and subjects of projects, but also on their proximity in the project-vector space. For example, the same methods or project management tools are used, the same performers are used, the same input information is used. If the vectors are the same, it means that the movements of the objects in these projects are identically defined. Therefore, a universal component of the multi-system project management of educational environments can be created, applicable to these projects.

To create an effective multisystem for managing projects in educational environments, the problem of grouping objects in the project-vector space of projects is formulated in such a way that the distance between the vectors of objects included in one group is minimal. The mathematical apparatus of vector algebra is used to calculate the distances between vectors and determine the optimal set of project groups (and, accordingly, subsystems of the multiproject management system). This ensured the creation of a mathematical model of an integral multisystem for managing projects of educational environments.

It is shown that the dimensions of the project-vector space reflect various evaluation categories (project values) that characterize the movement of objects in the project-vector space. As a result of the research, a list of the most significant objects and subjects of the project-vector space for the multisystem of project management of educational environments was obtained. In order to set the dimensions of the project-vector space, along which movements are carried out, all objects/subjects of the project-vector space are divided into groups: projects; project products; project tools; project subjects.

It is shown that in the spectrum of the project-vector approach, the introduced measurements serve as criteria for the certainty of the project goals. The goal in the project-vector space is represented through some abstract point, the achievement of which provides a given level of satisfaction for the project stakeholders. In this case, the degree of achievement of the project goal is represented through the vector of movement of objects of the project-vector space in 
the process of its implementation. The goals will be achieved if the actual coordinates of the objects in the project-vector space are equal to the target ones.

- For effective management of project goals based on the project-vector approach, a mathematical model of goal-setting in the project-vector space has been developed.

- It is shown that in order to create tools for a multi-system project management of educational environments, it is necessary to develop a method for determining such project goals (project goal setting) that will correspond to the maximum expansion of the "Universe of projects" and a method for calculating the trajectory of movement in the project-vector space that ensures the achievement of project goals with minimal waste of time and financial resources.

\section{Acknowledgments}

The article was written within the framework of the state order for the implementation of a scientific program under the budget program 217 «Development of Science», IRN №AP08857218 on the topic: «Information technology for assessment of scientific activity of universities, research institutes and their subdivisions».

\section{References}

1. Cliffort, F.G. (2003). Upravlenie proektami: prakticheskoe rukovodstvo [Project management] / F.G. Clifffort, E.W. Larson. - M.: Business and Service, 528.

2. Kovalenko, N. V. (2009). Kriterial'nyj podhod k upravleniju kachestvom $v$ mul'tiproektnoj srede proektno-orientirovannyh kompanij. [An indicative approach to quality management in a multiproject environment of project-oriented companies]. Project management and production development, (1 (29)).

3. Kamenskaya, V. (2009). Strategicheskie napravlenija upravlenija vuzov v uslovijah realizacii innovacionnyh proektov [Strategic directions of university management in the context of the implementation of innovative projects]. Economic Bulletin of the University, 11, 1-11.

4. Rach, V. A., Kolyada, O. P., \& Antonyan, E. A. (2009). Metod invariantnyh pokazatelej opisanija strategij razvitija kak instrument formirovanija portfelja proektov. [The method of invariant indicators for describing development strategies as a tool for forming a portfolio of projects]. Project management and development, (2 (30)).

5. Teslya, Y.N. (2010). Introduction to informatics of Nature: Monograph. K.: Maklaut, 2010.-255.

6. Turner, J. (2007). A guide to project-oriented management. Moscow: Dom Grebennikova.

7. Holod, B.I. (2012). Sovremennyj instrumentarij vybora operacionnyh strategij razvitija VUZov. [Modern tools for choosing operational strategies for the development of universities]. Academy review, 1(36), 5-12.

8. The Standard for Portfolio management / Project Management Institute, Inc. Four Campus Boulevard Newtown Square, Pennsylvania USA, 2008, 203.

9. Laszlo, C.A., Levine, M.D., \& Milsum, J.H. (1974). A general systems framework for social systems. Behavioral Science, 19(2), 79-92.

10. Biloshchytskyi, A.A. (2012). Model' rasshirjajushhejsja vselennoj proektov v upravlenii obrazovatel'nymi sredami. [Model of the expanding universe of projects in the management of educational environments]. Eastern European Journal of Advanced Technologies, 1(11 (55)), 41-43.

11. Biloshchytskyi, A.A. (2012). Vektornyj metod celepolaganija proektov v proektno-vektornom prostranstve. [Vector method of goal-setting projects in the project-vector space]. Management of Development of Complex Systems, 11, 110-114.

12. Biloshchytskyi, A.A. (2010). Upravlenie vysshimi uchebnymi zavedenijami s primeneniem metodov upravlenija proektami. [Management of higher educational institutions with the use of project management methods]. Management of Development of Complex Systems, 3, 87-91. 